\title{
Tapered Tube, Microsecond Electron Beam Gyrotron Backward-Wave-Oscillators
}

\author{
R. M. Gilgenbach, M. T. Walter, P. R. Menge, and T. A. Spencer* \\ Intense Energy Beam Interaction Laboratory, Nuclear Engineering Department \\ University of Michigan, Ann Arbor, MI 48109-2104
}

\begin{abstract}
Experiments have been performed to test microwave efficiency enhancement and pulselength extension of the gyrotron-backward- wave-oscillator (gyro-BWO) through the use of a tapered interaction tube. The MELBA accelerator has been utilized to generate electron beams with parameters: $\mathrm{V}=-0.7$ to $-0.8 \mathrm{MV}, \mathrm{I}=1-4 \mathrm{kA}$, and pulselengths from $0.5-1 \mu \mathrm{s}$. The microwave frequency is magnetically tunable in the range from $4.6-6 \mathrm{GHz}$. MAGIC code modeling has guided the experimental selection of taper magnitudes to enhance efficiency and pulselength. The optimal taper magnitude found in both the experiment and model has been a $10 \%$ downtapered tube, which gave a significant increase in both microwave tube power (factor of $\sim 2$, up to about $80 \mathrm{MW}$ ) and pulselength $(\approx 30 \%$ average increase up to $0.38 \mu \mathrm{s})$ over uniform tubes. Integrated microwave pulse-energy is also maximized for the $10 \%$ downtapered tube. Taper magnitudes larger than $10 \%$ gave reduced microwave power and energy.
\end{abstract}

\section{INTRODUCTION}

High power, long-pulse, microwaves have many applications in RF accelerators, defense electronics testing, and plasma heating. One of the major challenges has been to simultaneously generate multimegawatt microwaves while maintaining the microwave oscillation mechanism over a fraction of a microsecond. During the past several years, the uniform tube gyrotron-backward- wave-oscillator (gyroBWO) $[1,2]$ has shown considerable promise for both high power and long pulse operation [3]. Recently, improvement in gyro-BWO performance has resulted from taperedinteraction tubes [4]. A summary of gyro-BWO experiments on tapered interaction tubes is presented here.

\section{EXPERIMENTAL CONFIGURATION}

The experimental configuration is depicted in Figure 1. Electron beams are generated by the Michigan Electron Long Beam Accelerator, MELBA, at diode parameters: voltage $=-0.7$ to $-0.8 \mathrm{MV}, \mathrm{I}_{\mathrm{diode}}=1-10 \mathrm{kA}$, and pulselengths $=0.5-1 \mu \mathrm{s}$. A velvet button cathode is utilized, which reduces diode closure, to provide relatively flat current. The diode magnetic field coils are pulsed to generate about 1 kG magnetic field. A graphite anode apertures the e-beam to $5 \mathrm{~cm}$ diameter. The beam enters a solenoidal magnetic field coil on the transport tube, which generates 3-8 kG. This range of magnetic field allows the frequency to be magnetically tuned from 4.6-6 GHz. A number of interaction tubes and orientations were run: 1) copper tube with uniform cross section and $1.9 \mathrm{~cm}$ radius ( $20 \mathrm{~cm}$ long), 2) tapered tube, average radius of $1.9 \mathrm{~cm}$ with $10 \%$ decrease in direction of ebeam propagation (defined here as downtaper or orientation), 3) tapered tube with average radius of $1.9 \mathrm{~cm}$ with 23\% taper (both + and - orientations tested), 4) tapered tube with average radius of $1.9 \mathrm{~cm}$ with $43 \%$ taper (both + and - orientations tested). Microwaves were extracted by an $\mathrm{S}$-band waveguide antenna at the diode-end of the machine.

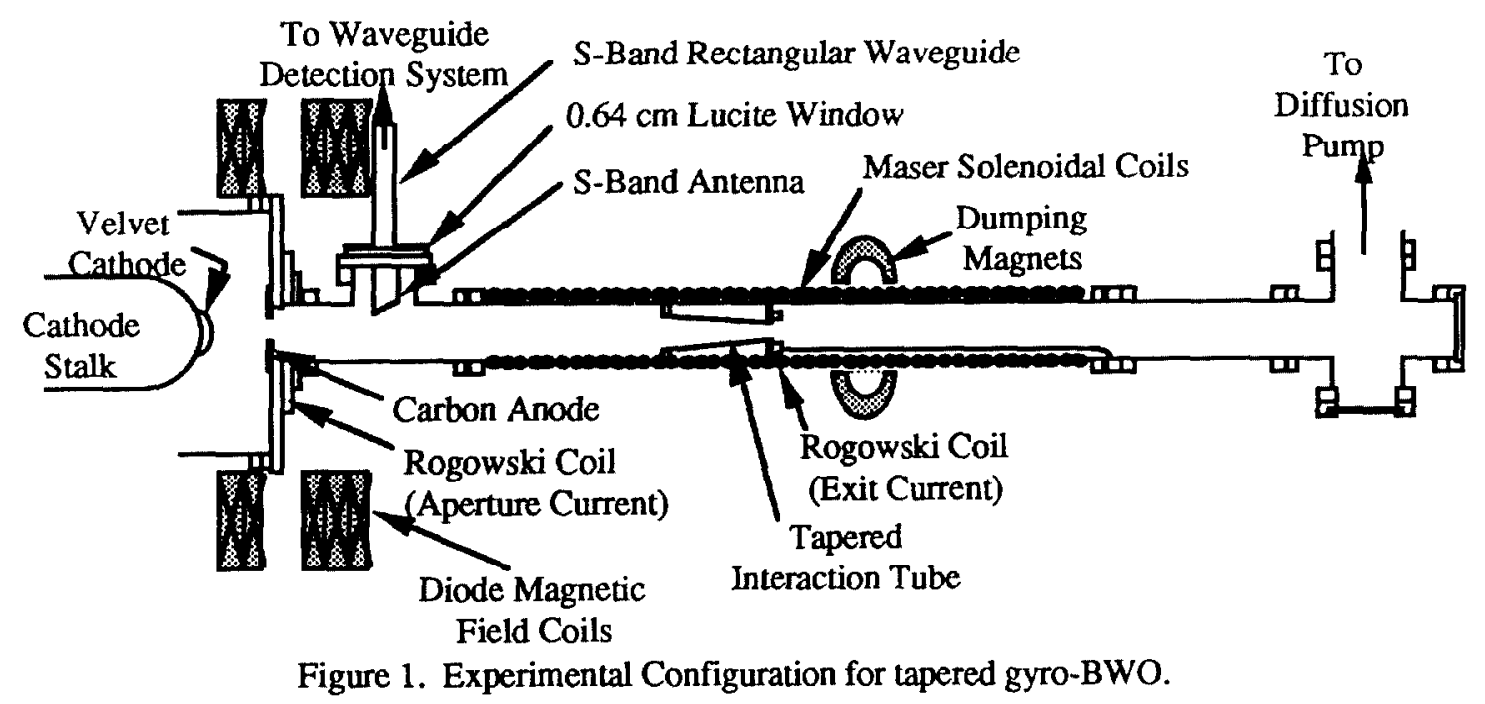

This research was supported by the Air Force Office of Scientific Research, Phillips Lab, and the AFOSR-sponsored MAGIC Code User's Group with Mission Research Corp. P.R. Menge also received a fellowship from the UM Rackham Graduate School.

* T.A. Spencer's permanent address is the Air Force Phillips Laboratory, Kirtland AFB, NM. 
Recent frequency-swept measurements of the microwave coupling have shown a maximum coupling efficiency of -7.5 $\mathrm{dB}(\sim 18 \%)$ between tube microwaves and this antenna. The gyro-BWO microwave output was split by directional couplers and further attenuated for measurement with calibrated diode detectors. Reflected microwaves were typically directed through a lucite window at the far end of the gyro-BWO into a large tank lined with microwave absorber.

\section{EXPERIMENTAL RESULTS}

Figures 2 and 3 show examples of gyro-BWO experimental signals detected for the uniform tube and the $10 \%$ downtapered tube. Voltage and current signals from MELBA are fairly flat over at least the first microsecond of the e-bean pulse. Generally, the microwave emission was longer and the power was higher for the $10 \%$ downtapered tube versus the uniform tube. Assuming the maximum value of coupling $(\approx 18 \%)$ between the tube and antenna, the peak microwave tube power (up to about $80 \mathrm{MW}$ ) for the $10 \%$

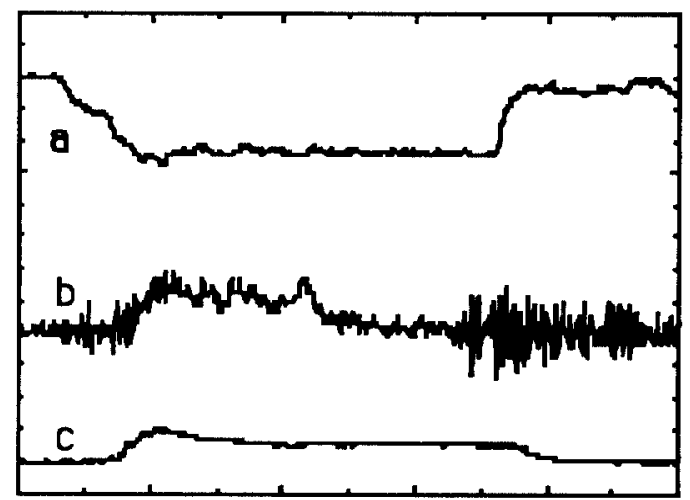

Figure 2. Data for gyro-BWO with uniform tube:

a) Beam voltage $(310 \mathrm{kV} / \mathrm{div})$,

b) Microwave detector signal ( $25 \mathrm{mV} / \mathrm{div})$.

c) Transported beam current $(2 \mathrm{kA} / \mathrm{div})$,

Solenoidal field is $5100 \mathrm{G}$.

Time scale is $100 \mathrm{~ns} /$ div. downtapered tube is more than a factor of two higher than the peak tube power $(\approx 30 \mathrm{MW})$ found thus far from the uniform tube. The high power microwave emission magnetic tuning band was much larger for the tapered tube, as expected.

MAGIC code simulations predicted that the gyroBWO power enhancement from tapered tubes was expected to be optimal for the $10 \%$ downtapered case, out of all the cascs run $( \pm 10 \%, \pm 23 \%, \pm 43 \%)$ This is in qualitative agreement with the experiments, which showed reduced power at tube tapers of $\pm 23 \%$ and $\pm 43 \%$, relative to the uniform-tube case.

Significant increases in the microwave pulselength were also observed with the $10 \%$ downtapered-tube gyroBWO, as seen in Figure 4. The average pulselength with the tapered tube was $380 \mathrm{~ns}$ compared with $300 \mathrm{~ns}$ for the uniform tube, about a $30 \%$ increase. By integrating digital oscilloscope microwave signals it was found that inferred integrated energy was also greater with the $10 \%$ downtapered tube, compared to the uniform case.

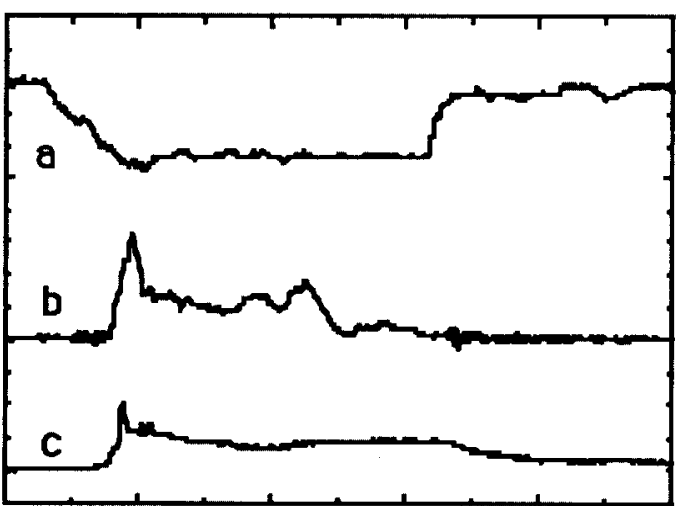

Figure 3. Data for gyro-BWO with $10 \%$ downtapered tube:

a) Beam voltage $(310 \mathrm{kV} / \mathrm{div})$,

b) Microwave detector signal $(100 \mathrm{mV} /$ div $)$.

c) Transported beam current ( $2 \mathrm{kA} / \mathrm{div})$, Solenoidal field is $5100 \mathrm{G}$.

Time scale is $100 \mathrm{~ns} / \mathrm{div}$. 

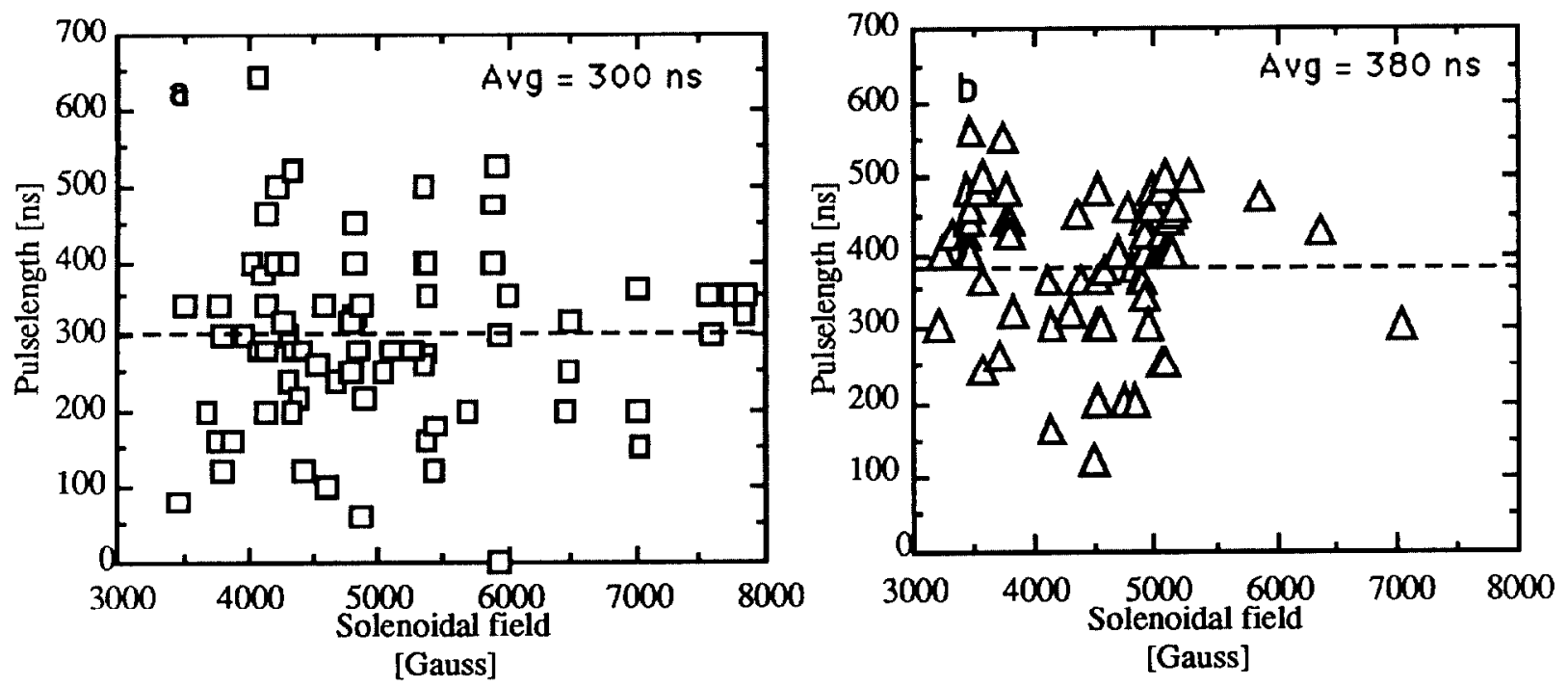

Figure 4. Microwave pulselength for gyro-BWO:

a) Uniform tube, and

b) Tube with $10 \%$ downtaper.

\section{ACKNOWLEDGMENTS}

We acknowledge valuable discussions with Professor Y.

Y. Lau. C. H. Ching and R. A. Lindley are acknowledged for experimental assistance.

\section{REFERENCES}

[1] S. Y Park, R. H. Kyser, C. M. Armstrong, R. K.

Parker, and V. L. Granatstein, IEEE Trans. Pl. Sc. Vol. 18, p. 321 (1990)

[2] A. K. Ganguli and S. Ahn, Appl. Phys. Lett. Vol. 54 , p. 514 (1989)

[3] T. A. Spencer, R. M. Gilgenbach, and J. J, Choi, J.

Appl. Phys. Vol. 72, p. 1221 (1992)

[4] R. M. Gilgenbach, M. T. Walter, P. R. Menge, and T.

A. Spencer, Proceedings of the 17th International

Conference on Infrared and Millimeter Waves, SPIE Vol.

1929 (1992). 